ISSN 1936-5098

CAE Working Paper \#11-02

\title{
Efficient Ramsey Equilibria
}

by

Robert Becker

and

Tapan Mitra

March 2011 


\title{
Efficient Ramsey Equilbria*
}

\author{
Robert A. Becker \\ Department of Economics \\ Indiana University \\ Bloomington, IN 47405 \\ USA
}

\author{
Tapan Mitra \\ Department of Economics \\ Cornell Universtiy \\ Ithaca, NY 14853 \\ USA
}

March 13, 2011

\begin{abstract}
Ramsey equilibrium models with heterogeneous agents and borrowing constraints are shown to yield efficient equilibrium sequences of aggregate capital and consumption. The proof of this result is based on verifying that equilibrium sequences of prices satisfy the Malinvaud criterion for efficiency.
\end{abstract}

\section{Introduction}

A fundamental question in macrodynamic models of capital accumulation concerns whether or not the economy is providing as much consumption as it can following a competitive equilibrium path. For optimal growth models, or their equivalent perfect foresight competitive economy counterparts, the answer is affirmative, at least for models with a representative infinitely lived household central planner. The optimal program of capital accumulation invests neither too much, nor too little, over time.

In a seminal paper Malinvaud [29] found sufficient conditions for identifying efficient programs. ${ }^{1}$ His theorem was designed to work within a wide range of model specifications, including models not yet developed when he wrote in the early 1950's on this matter. Since that time, representative agent, and heterogenous agent models of capital accumulation with infinitely-lived households

${ }^{*}$ Robert Becker is grateful to the organizers of the Conference on Agents Interactions, Market Independences, and Aggregate Instabilities (Paris, June 2009) for their financial support and invitation to discuss Bloise and Reichlin's paper [19], which inspired this article. Special thanks go to Jess Benhabib, Gaetano Bloise, and Jean-Pierre Drugeon for comments and discussions during that conference.

${ }^{1}$ The broader search for a complete characterization of efficient programs, at least in one sector models, was resolved by Cass [20]. The references include citations to key works that generalized and extended Cass efficiency criterion following the publication of [20]. 
endowed with perfect foresight over the future paths of prices absent technological uncertainty, or idiosyncratic risks, have been developed by a number of economic theorists. ${ }^{2}$

For models where the equilibrium program may not necessarily solve a social welfare problem it is interesting to learn if the resulting path of capital accumulation is efficient and society is providing as much consumption as possible, even if that consumption is not necessarily achieving a Pareto optimal distribution. One class of these models, a form of the many-agent Ramsey model, consider heterogeneous infinitely-lived agents with different rates of discounting future utility in a one-sector perfect foresight model. This framework, inspired by Ramsey [35], can be found in a series of papers following Becker's [2] formulation, and proof, of the existence of a unique stationary equilibrium in which only the most patient household owns capital. The key structural assumption in Becker's formulation is that households are forbidden to borrow against their anticipated future wage income. They are borrowing constrained. This makes the model one with incomplete markets in a certainty setting.

The welfare properties of these models has gone unexplored. Examining whether or not the Ramsey equilibria from arbitrary initial distributions of capital across the households are efficient is a first step in the welfare analysis of these equilibria. The purpose of this paper is to prove that the aggregate capital sequence found in Ramsey equilibrium models is efficient. The proof is qualified by a mild restriction on the class of equilibria that includes all the currently known examples.

Malinvaud's Sufficiency Theorem highlights the way in which the efficiency criterion focuses solely on aggregate consumption, and not how it is distributed to individuals. The test for efficiency only makes use of the total consumption produced in an equilibrium at each time, and not its allocation to particular individuals. Yet, we will see that how private individuals actually value their marginal consumption at each time plays a fundamental role in detecting whether or not an equilibrium is, in fact, giving rise to an efficient allocation of society's scarce capital and providing the most consumption possible in the aggregate. Since the model in question is one with incomplete markets, it is not reasonable to expect a form of the first welfare theorem to obtain. However, demonstrating the resulting equilibrium is efficient is a minimal welfare test. The paper's main result is that the Ramsey equilibrium aggregate capital sequences are efficient provided that the most patient household's capital stock is eventually positive, and remains positive thereafter. This condition is sufficient to identify (eventually) that agent's subjective prices and the market prices. This agent's subjective prices obey a transversality condition which is transmitted to the marketplace since this agent's capital is eventually positive and remains so in subsequent periods. This transversality condition is used to demonstrate efficiency obtains according to the Malinvaud criterion.

Previous literature on efficiency in incomplete markets addressed this question in stochastic overlapping generations models as well as in models of infinitely-

\footnotetext{
${ }^{2}$ This paper's bibliography includes many such selections.
} 
lived consumers operating in exchange economies with goods defined by their dates of availability and as state-contingent claims. The paper by Bloise and Reichlin [19], which inspired the present work, is a good example of this previous literature. ${ }^{3}$ They study an exchange economy of infinitely-lived agents consuming a single good at each date, the availability of which is determined as a state-contingent event. They place borrowing constraints of various types on their consumers and ask whether or not the resulting competitive equilibrium is efficient. They generalized Cass' criteria to answer this problem affirmatively in their different settings. A key step in their arguments (as well as in Alvarez and Jermann [1]) is verification that consumers' subjective valuations satisfy a maximum condition. The deterministic, production based, Ramsey equilibrium model of our paper exhibits a transversality condition in equilibrium and efficiency is verified by applying Malinvaud's Theorem rather than the Cass Characterization Theorem [20].

\section{The Malinvaud Criterion for Efficiency}

Time is taken in discrete intervals, $t=1,2, \ldots$ Real (vector)-valued sequences are written $\left\{x_{t}\right\}_{t=1}^{\infty}$, or as $\left\{x_{t}\right\}$ when the time index's range is clear. A realvalued sequence is non-null if each componenent is nonzero, and it is nonnegative if each component is nonnegative, that is, $x_{t} \geq 0$ for each $t$.

The Malinvaud criterion for efficiency in a one-sector model of capital accumulation is reviewed in this section. Production takes place using a single capital good. The productive technology turns labor and capital goods into a composite good that can be either consumed or saved as next period's capital input. The amount of labor is fixed in this economy (there will be one unit of labor services per household and all labor services are assumed to be identical). The technology is summarized by a production function, denoted by $f$. Let $y=f(k)$ denote the composite good $y$ produced from a fixed amount of labor (whose value is suppressed in the notation), together with a nonnegative capital input $k$. Capital is assumed to depreciate completely within the period. Hence, the model is formally one with circulating capital that is consumed within the production period. The output $y$ is available for consumption or capital accumulation with a one-period lag. The formal properties of $f$ are recorded as Assumption I.

Assumption I: $f: \mathbb{R}_{+} \rightarrow \mathbb{R}_{+}, f(0)=0, f$ is $C^{(2)}$ on $\mathbb{R}_{++}, f^{\prime}>0, \lim _{x \rightarrow 0} f^{\prime}(k)=$ $\infty, \lim _{x \rightarrow \infty} f^{\prime}(k)=0$, and $f^{\prime \prime}<0$.

\footnotetext{
${ }^{3}$ See also Alverez and Jermann [1], Bloise and Calciano [18], and Chattopadhyay and Gottardi [23] for works using Cass criteria developed for stochastic models with various forms of market incompletion, including default and borrowing constraints. Bloise [17] developed a modified Cass criterion for examining "uniform" efficiency in deterministic overlapping generations models. Chattopadhyay [24] reexamined the problem of connecting dividend payouts in deteministic models with overlapping generations to explore when dividend streams are usable for proving the economy is on an efficient path.
} 
The conditions $f^{\prime}(0+)=+\infty$ and $f^{\prime}(\infty)=0$ are the production function's Inada conditions. This assumption implies there is a maximum sustainable capital stock, denoted $B$, satisfying $B=f(B)>0$. Denote $\mathbb{R}_{+}=[0, \infty)$ and $\mathbb{R}_{++}=(0, \infty)$.

The capital stock sequence $\left\{K_{t-1}\right\}, t=1,2 \ldots$ is a capital stock program $\left(K_{t} \geq 0\right.$ all $\left.t\right)$ if

$$
f\left(K_{t-1}\right)-K_{t} \geq 0 \text { for each } t \geq 1 \text {. }
$$

The corresponding consumption program is $\left\{C_{t}\right\}$ with $C_{t}=f\left(K_{t-1}\right)-K_{t}$. The capital stock program and corresponding consumption programs are feasible if $K_{0}=\mathbf{k}>0$, where $\mathbf{k}$ is the given starting stock. Assumption AI implies that if the initial aggregate capital stock $\mathbf{k}$ is smaller than $B$, then all nonnegative sequences of consumption and capital satisfying the balance condition, $C_{t}+K_{t}=$ $f\left(K_{t-1}\right)$ for all $t$ with $K_{0}=\mathbf{k}$, are bounded from above by $B$.

A feasible capital stock program $\left\{K_{t}^{\prime}\right\}$ dominates the feasible capital stock program $\left\{K_{t}\right\}$, with $K_{t} \neq K_{t}^{\prime}$ for some $t$, if the corresponding consumption program, $\left\{C_{t}^{\prime}\right\}$ has the property:

$$
C_{t}^{\prime} \geq C_{t} \text { for all } t \text {, with }>\text { for some } t .
$$

A feasible capital stock program which is dominated is called inefficient; otherwise, it is said to be efficient.

Associated to any feasible capital program $\left\{K_{t}\right\}$, where $K_{t}>0$ for all $t \geq 1$, is a sequence of shadow prices $\left\{p_{t}\right\}$, or competitive prices, which are recursively defined by

$$
p_{0}=1, p_{t+1} f^{\prime}\left(K_{t}\right)=p_{t}, t \geq 0 .
$$

These prices are also the ones implied or derived from $\left\{K_{t}\right\}$. Note that such a price sequence has the property (given $f$ is concave):

$$
p_{t+1} f\left(K_{t}\right)-p_{t} K_{t} \geq p_{t+1} f(x)-p_{t} x \text { for each } x \geq 0 \text { and each } t \geq 0 .
$$

This is the period-wise (or intertemporal) profit maximizing condition. The prices defined in this manner are strictly positive as $K_{t}>0$ for each $t$.

In general, a sequence $\left\{K_{t}, p_{t}\right\}$ is intertemporal profit maximizing if $\left\{K_{t}\right\}$ is a feasible capital program starting from $k_{0}>0,\left\{p_{t}\right\}$ is a non-null, nonnegative price sequence, and (1) obtains for each $t \geq 0$.

Starting with Malinvaud [29] many authors have shown a close connection between shadow prices and ascertaining whether or not the underlying feasible program is efficient. ${ }^{4}$

The Malinvaud Sufficiency Theorem [29] is:

Theorem 1 Assume $f$ satisfies AI. If a sequence $\left\{K_{t}, p_{t}\right\}$ is intertemporal profit maximizing, with $p_{t}>0$ for each $t \geq 0$, and:

$$
\lim _{t \rightarrow \infty} p_{t} K_{t}=0,
$$

then $\left\{K_{t}\right\}$ is efficient.

\footnotetext{
${ }^{4}$ See Beneveniste ([11], [12]), Beneveniste and Gale ([13], [14]), Cass ([20],[21]), and Mitra [31] for general criteria for efficiency in one-sector models.
} 
It is sufficient to verify $p_{t} \rightarrow 0$ as $t \rightarrow \infty$ for the models appearing in this paper. See the Section 6 for an argument supporting this claim.

Application of Malinvaud's Theorem requires calculating the shadow prices. This is readily done for the case of the one-sector discounted Ramsey model of optimal growth. Well-known necessary and sufficient conditions include satisfaction of a transversality condition in the form (2). In fact, The shadow prices $\left\{p_{t}\right\}$ associated with the optimal program have the property $p_{t} \rightarrow 0$ as $t \rightarrow \infty$, at least in the case where the economy has a maximum sustainable capital stock. So, the optimum $\left\{K_{t-1}\right\}$ is efficient. Moreover, it is also straightforward to interpret the sequence of shadow prices as competitive market prices using standard equivalence principles (see [4]). This interpretation also tells us that market prices, $\left\{p_{t}\right\}$, can be used to detect whether or not the corresponding equilibrium program is efficient. Of course, this result is obvious simply from the fact that an optimal capital sequence is under consideration. However, it previews the arguments made below.

The single agent model's discounted price system implicitly defines an equilibrium capital goods rental rate in each period via the period-wise profit maximizing necessary condition $p_{t+1} f^{\prime}\left(K_{t}\right)=p_{t}, t \geq 0, p_{0}=1$, by setting $f^{\prime}\left(K_{t}\right)=$ $1+r_{t+1}$. In the multi-agent Ramsey model the market price sequence $\left\{p_{t}\right\}$ will be imputed from the profit condition $f^{\prime}\left(K_{t}\right)=1+r_{t+1}$ with $p_{0}=1$ defining the numeraire.

\section{The Ramsey Equilibrium Model}

The Ramsey equilibrium model is briefly described below. Agents preferences assume time additively separable utility functions with fixed discount factors. The technology is specified by a one-sector model with a single all purpose consumption-capital good as above.

The general complete market competitive one-sector model treats budget constraints as restricting the present value of an agent's consumption to be smaller than or equal to the agent's initial wealth defined as the capitalized wage income plus the present value of that person's initial capital. This allows us to interpret the choice of a consumption stream as if the agent is allowed to borrow and lend at market determined present value prices subject to repaying all loans. Markets are complete - any intertemporal trade satisfying the present value budget constraint is admissible at the individual level. The Ramsey equilibrium model changes the budget constraint from a single one (reckoned as a present value) to a sequence, one for each period. Agents are forbidden to borrow against their future labor income, so they cannot capitalize the future wage stream into a present value. Markets are incomplete; individuals are debt constrained. The operation of a borrowing constraint in the individual household problems also breaks the possibility of an equilibrium allocation arising as the economy's optimal allocation. 


\subsection{The Basic Model and Blanket Assumptions}

There are $H \geq 1$ households indexed by $h=1, \ldots, H$. There is a single commodity available for consumption or investment at each time. At time zero, households are endowed with capital stocks $k^{h} \geq 0$. Put $\mathbf{k}=\sum_{h} k^{h}$ and assume $\mathbf{k}>0$. Let $c_{t}^{h}, x_{t}^{h}$ denote the consumption and capital stock of household $h$ at time $t$. Household $h$ has felicity function $u_{h}$ (also known as the temporal utility function or single-period return function); $c_{t}^{h}$ is the argument of $u_{h}$. Household $h$ discounts future utilities by the factor $\delta_{h}$ with $0<\delta_{h}<1$. Hence, the household's lifetime utility function is specified by $\sum_{t=1}^{\infty} \delta_{h}^{t-1} u_{h}\left(c_{t}^{h}\right)$.

Assumption II: For each $h, u_{h}: \mathbb{R}_{+} \rightarrow \mathbb{R}$ is $C^{(2)}$ on $\mathbb{R}_{++}$with $u_{h}^{\prime}>$ $0, u_{h}^{\prime \prime}<0$, and $\lim _{c \rightarrow 0} u^{\prime}(c)=\infty$.

The model has common discount factors when all agents' discount factors are equal, and heterogeneous discount factors otherwise. This paper's focus is on the heterogeneous case. The major results only require two types - one household is the most patient and the others are less patient. This is expressed by assuming the first household's discount factor is larger than all the other households' discount factors. The first household is the most patient agent and the others are said to be less patient than the first one. Assumption III orders households from the most patient to the least patient.

Assumption III: $1>\delta_{1}>\delta_{2} \geq \cdots \geq \delta_{H}>0$.

Production takes place using a single capital good as set out in Section 2. Assumptions I-III are blanket assumptions assumed for the remainder of this article and sometimes referred to as $(A I)$-(AIII). If $H=1$, then the Ramsey equilibrium model coincides with the standard optimal growth problem. Assume $H \geq 2$ in the sequel.

\subsection{The Households' Problems}

Let $\left\{1+r_{t}, w_{t}\right\}$ be a sequence of one period rental factors and wage rates, respectively. The sequences $\left\{1+r_{t}, w_{t}\right\}$ are always taken to be nonnegative and nonzero. Households are competitive agents and perfectly anticipate the profile of factor returns $\left\{1+r_{t}, w_{t}\right\}$. Given $\left\{1+r_{t}, w_{t}\right\}, h$ solves

$$
P(h): \sup \sum_{t=1}^{\infty} \delta_{h}^{t-1} u_{h}\left(c_{t}^{h}\right)
$$

by choice of nonnegative sequences $\left\{c_{t}^{h}, x_{t}^{h}\right\}$ satisfying $x_{0}^{h}=k^{h}$ and

$$
c_{t}^{h}+x_{t}^{h}=w_{t}+\left(1+r_{t}\right) x_{t-1}^{h},(t=1,2, \ldots) .
$$

The market structure of this model requires capital assets to be nonnegative at each moment of time and that agents without capital cannot borrow against the discounted value of their future wage income. 
The No Arbitrage or Euler necessary conditions for $\left\{c_{t}^{h}, x_{t}^{h}\right\}$ to solve $P(h)$ are $c_{t}^{h}>0$ and

$$
\delta_{h}\left(1+r_{t+1}\right) u_{h}^{\prime}\left(c_{t+1}^{h}\right) \leq u_{h}^{\prime}\left(c_{t}^{h}\right)
$$

for each $t$ with equality whenever $x_{t}^{h}>0$. If $x_{t}^{h}>0$, then the inequality in (4) can be reversed resulting in the Euler equation:

$$
\delta_{h}\left(1+r_{t+1}\right) u_{h}^{\prime}\left(c_{t+1}^{h}\right)=u_{h}^{\prime}\left(c_{t}^{h}\right) .
$$

The corresponding transversality condition is

$$
\lim _{t \rightarrow \infty} \delta_{h}^{t-1} u_{h}^{\prime}\left(c_{t}^{h}\right)=0,
$$

which also implies $\lim _{t \rightarrow \infty} \delta_{h}^{t-1} u_{h}^{\prime}\left(c_{t}^{h}\right) x_{t-1}^{h}=0$ since $\left\{x_{t-1}^{h}\right\}$ is a bounded sequence.

\subsection{The Production Sector's Objective}

The production sector is characterized by the one sector neoclassical production function $f$ described in Section 2. Assumption I describes the economy's technological properties.

All the intertemporal decisions are taken in the household sector. Producers are supposed to take the rental rate as given and solve the following myopic profit maximization problem $P(F)$ at each $t$ :

$$
P(F): \sup \left[f\left(x_{t-1}\right)-\left(1+r_{t}\right) x_{t-1}\right]
$$

by choice of $x_{t-1} \geq 0$. The residual profit is treated as the wage bill. It is shared equally by the identical households as wages - production is worker owned.

If $0<1+r_{t}<\infty$, then $(A I)$ implies there is a unique positive stock $K_{t-1}$ which solves $P(F)$ at each $t$; clearly

$$
f^{\prime}\left(K_{t-1}\right)=1+r_{t}
$$

furthermore, the corresponding $\left\{w_{t}\right\}$ defined by

$$
H w_{t}=f\left(K_{t-1}\right)-\left(1+r_{t}\right) K_{t-1}
$$

is positive.

\subsection{The Ramsey Economy}

A collection $\mathcal{E}=\left(f,\left\{u_{h}, \delta_{h}, k^{h}\right\}, h=1,2, \ldots, H\right)$ satisfying Assumptions I-III, and for which $k^{h} \geq 0$ for each $h$ with $\mathbf{k}=\sum_{h=1}^{H} k^{h}>0, \mathbf{k} \leq B$, is said to be a Ramsey economy, or simply, an economy. A given economy is thus a collection of primitives on tastes and technology that meets the basic assumptions for households and the production sector. The economy is always assumed to have a positive aggregate capital stock that is also no larger than the maximum sustainable stock. Individual endowments of capital may or may not be positive. However, at least one agent will always possess some capital at time zero. 


\subsection{The Equilibrium Concept}

The equilibrium concept is perfect foresight. Households perfectly anticipate the sequences of rental and wage rates. They solve their optimization problems for their planned consumption demand and capital supply sequences. The production sector calculates the capital demand at each time and the corresponding total output supply. Rentals are paid to the households for capital supplied and the residual profits are paid out as the total wage bill. An equilibrium occurs when the households capital supply equals the production sector's capital demand at every point of time. A form of Walras' Law implies that the total consumption demand and supply of capital for the next period equals current output. Thus, in equilibrium, every agent is maximizing its objective function and planned supplies equal planned demands in every market.

Definition 2 Sequences $\left\{1+r_{t}, w_{t}, K_{t-1}, c_{t}^{h}, x_{t-1}^{h}\right\}$ constitute a Ramsey Equilibrium for a given economy $\mathcal{E}$ provided:

E1. For each $h,\left\{c_{t}^{h}, x_{t-1}^{h}\right\}$ solves $P(h)$ given $\left\{1+r_{t}, w_{t}\right\}$.

E2. For each $t, K_{t-1}$ solves $P(F)$ given $1+r_{t}$.

E3. $H w_{t}=f\left(K_{t-1}\right)-\left(1+r_{t}\right) K_{t-1}(t=1,2, \ldots)$.

E4. $\sum_{h=1}^{H} x_{t-1}^{h}=K_{t-1}(t=1,2, \ldots), 0<\mathbf{k}=K_{0} \leq B$.

Thus, consumers maximize utility (E1) and producers maximize profits (E3). The labor market clearing condition is expressed in (E3). The capital market clearing condition is (E4). The output market balance follows by combining (E1)- (E4). This is a form of Walras' Law that holds at each time. Hence

$$
\sum_{h=1}^{H}\left(c_{t}^{h}+x_{t}^{h}\right)=f\left(K_{t-1}\right) .
$$

Note that equilibrium consumption and capital sequences are bounded from above by the maximum sustainable stock. The assumed Inada conditions for households and the producer imply that in an equilibrium $c_{t}^{h}>0$ and $K_{t-1}>0$ for each $t$, given that $\mathbf{k}$ is positive, and each agent's income, $w_{t}+\left(1+r_{t}\right) x_{t-1}^{h}>0$ at each time, even if $x_{t-1}^{h}=0$. Moreover, at least one household's capital stock is positive at each time along an equilibrium profile.

Given an equilibrium path, the corresponding aggregate capital sequence and consumption sequence are defined by the formulas $K_{t}=\sum_{h=1}^{H} x_{t}^{h}$ and $C_{t}=$ $\sum_{h=1}^{H} c_{t}^{h}$, respectively. The Malinvaud criterion for testing efficiency is applied to these sequences.

\section{Properties of Ramsey Equilibria}

A Ramsey equilibrium program is stationary for the economy $\mathcal{E}$ provided the equilibrium wage rate, rental rate, the aggregate capital stock, and the allocations of capital and consumption are constant over time. Becker [2] proves 
the existence of a unique stationary equilibrium in which only the most patient household has capital - all other households have none and live off their wage incomes. Of course, this most patient consumer also has a wage income, so that person achieves a higher consumption level than the others.

Let $K^{\delta_{1}}$ be the unique solution to the equation $f^{\prime}(k)=\left(1 / \delta_{1}\right)$. This capital stock is the first household's capital and the stationary aggregate capital stock in the stationary equilibrium solution described in Becker [2]. Stationary aggregate consumption is found at each time by adding the economy's wage bill to the rental income received by the most patient household.

The relatively impatient households have no physical assets in the stationary equilibrium. So, if that equilibrium is stable, it must be the case that those households capital holdings converge to zero. This is not always true in a Ramsey equilibrium. However, there is a weaker property that is characteristic of any equilibrium path. This is the recurrence property.

General properties of equilibrium paths found under Assumptions I-III are briefly summarized below. Formal details and proofs are in the referenced papers (e.g, see [6]). Fix the economy $\mathcal{E}$ meeting Assumptions (I-III).

(P1) Equilibria exist. ${ }^{5}$

(P2) If $\left\{1+r_{t}, w_{t}, K_{t-1}, c_{t}^{h}, x_{t-1}^{h}\right\}$ is a Ramsey equilibrium for $\mathcal{E}$, then the no capital state is recurrent for each $h \geq 2$. That is, for each $h \geq 2, x_{t}^{h}=$ 0 infinitely often. This Recurrence Theorem is the most general result in the literature on the properties enjoyed in a dynamic Ramsey equilibrium. This result cannot be improved upon without additional restrictions on the model.

(P3) For each equilibrium, $\lim \sup _{t \rightarrow \infty} K_{t-1} \geq K^{\delta_{1}}$. This result does not exclude the capital sequence from exceeding the Golden-Rule capital stock, $K^{g}$, infinitely often, where $K^{g}$ is defined as the solution to $f^{\prime}(k)=1$. This is important as this situation could be a way for a path to be inefficient. Cass [20] notes that a periodic path could be efficient, or inefficient, if it oscillated around the Golden-Rule stock. ${ }^{6}$ The two-period cycles found by Becker and Foias [6] and Stern [38] oscillate around the golden-rule stock, so they are potential counterexamples to the general efficiency of Ramsey equilibrium programs. Period two equilibrium cycles are shown below to be efficient.

(P4) Each household's consumption is bounded away from zero along an equilibrium path. That is, $\eta^{h} \equiv \inf _{t} c_{t}^{h}>0(h=1,2, \ldots, H)$ holds in each equilibrium. ${ }^{7}$

\footnotetext{
${ }^{5}$ See Becker, Boyd, and Foias [5] for general existence theorems that apply to the additive separable utility cases in this paper, as well as for broader recursive utility specifications.

${ }^{6}$ See Cass ([20], p. 214).

${ }^{7} \mathrm{~A}$ formal proof of this fact is available on request from Robert Becker as a Technical Appendix.
} 
The property, $\eta^{h}>0(h=1,2, \ldots, H)$, implies no agent consumes zero or even approaches zero consumption asymptotically. This result distinguishes the Ramsey model with borrowing constraints from its complete market general equilibrium counterparts as found in Bewley [16], Coles ([25], [26]), Duran and Le Van [27], Le Van and Vailakis [28], and Rader ([32], [33], and [34]). This lower bound for agent's consumption sequences is the critical property that is used to show the appropriate sequence of supporting prices satisfies the transversality condition sufficient for efficiency.

The Recurrence Theorem tells us households $h \geq 2$ achieve the zero capital state infinitely often. At any time in which such an agent's capital is zero, the agent can always consume less than its current wage income and thereby achieve a positive capital state one period later. It would be nice from an analytical view if once a household achieved a zero capital state, it maintained that state for all remaining times. Unfortunately, that is not the case in general. This fact is illustrated by an example due to Michael Stern [38], which is discussed at length in the survey paper in [3].

The turnpike property obtains if every $h \geq 2$ eventually reaches a no capital position and maintains that state thereafter. Stern's example shows that without additional assumptions on technology and/or preferences, the turnpike property does not obtain. Yet, it does hold in some economies. The turnpike property holds whenever each household $h \geq 2$ is sufficiently myopic in comparison to the first household's discount factor. ${ }^{8}$ The turnpike property also obtains whenever the equilibrium aggregate capital stock sequence is convergent and that limit must be the steady state stock. ${ }^{9}$

\section{The Efficiency of a Ramsey Equilibrium Pro- gram}

The definition of an efficient capital stock sequence is applied to the aggregate capital stock sequence, $\left\{K_{t-1}\right\}$, in an economy $\mathcal{E}$ satisfying (AI)-(AIII) given the equilibrium $\left\{1+r_{t}, w_{t}, K_{t-1}, c_{t}^{h}, x_{t-1}^{h}\right\}$ with the fixed initial condition $\mathbf{k}=\sum_{h=1}^{H} k^{h}$. In this case, $K_{t-1}=\sum_{h=1}^{H} x_{t-1}^{h}$ and the corresponding aggregate consumption is the sequence $\left\{C_{t}\right\}$ with $C_{t}=\sum_{h=1}^{H} c_{t}^{h}$. The paths $\left\{K_{t-1}, C_{t}\right\}$ are feasible from the initial stocks $\mathbf{k}$ (the distribution of initial capital across households does not enter the discussion). For the purposes of efficiency analysis, the question is whether or not the aggregate capital stock sequence $\left\{K_{t-1}\right\}$ is dominated by another feasible aggregate capital sequence $\left\{K_{t-1}^{*}\right\}$ with its corresponding aggregate consumption $\left\{C_{t}^{*}\right\}$ defined period-wise by $C_{t}^{*}=f\left(K_{t-1}^{*}\right)-K_{t-1}^{*}, K_{0}^{*}=\mathbf{k}$. The test of whether or not $\left\{K_{t-1}\right\}$ is dominated by a particular $\left\{K_{t-1}^{*}\right\}$ places no restrictions on how $C_{t}^{*}$ is allocated to

\footnotetext{
${ }^{8}$ See Becker and Tsyganov's paper (Lemma 4.4),[10]). Their result is derived for a twosector model, but applies to one-sector models upon assuming both sectors have indentical production functions.

${ }^{9}$ See Becker and Foias (Propositions 4 and 5 in [6]) for a proof.
} 
the individual households at any time $t$. The efficiency criterion simply does not take distribution of consumption across agents into account in judging one feasible aggregate capital sequence compared to another. Total consumption at each time is all that matters when efficiency is discussed.

\subsection{Efficient Programs: Two Examples}

Efficiency of the equilibrium $\left\{K_{t-1}\right\}$ can be verified directly in some cases where a priori qualitative or quantitative information about the equilibrium aggregate capital sequence is known.

\subsubsection{Example 1: A Monotone Increasing Capital Stock Sequence}

Becker and Foias [6] show that if in addition to $A I$-AIII the capital income monotonicity condition holds, then the sequence $\left\{K_{t-1}\right\}$ is eventually monotonic and converges to $K^{\delta_{1}}$ as $t \rightarrow \infty$. Capital income monotonicity holds if $f^{\prime}(k) k$ is an increasing function of $k$; it is satisfied if $f(k)=A k^{\alpha}$ for some $A>0$ and $0<\alpha<1$.

Consider the general case where $K_{t} \rightarrow K^{\delta_{1}}$. Since $f^{\prime}\left(K^{\delta_{1}}\right)=\left(1 / \delta_{1}\right)>1$, and $\theta \equiv\left[1+\left(1 / \delta_{1}\right)\right] / 2$ satisfies $1<\theta<\left(1 / \delta_{1}\right)$, concavity of $f$ on $\mathbb{R}_{+}$and continuity of $f^{\prime}$ on $\mathbb{R}_{++}$imply that there is a positive integer $T$ such that for all $t \geq T$, we have $f^{\prime}\left(K_{t}\right) \geq \theta>1$. Thus $\left\{p_{t}\right\}$ defined in above satisfies $p_{t} \rightarrow 0$ as $t \rightarrow \infty$, and $\left\{K_{t}\right\}$ is efficient by Malinvaud's sufficiency theorem.

\subsubsection{Example 2: A Two-Period Equilibrium Capital Stock Sequence}

Periodic equilibrium capital sequences present challenges for demonstrating the aggregate capital sequence is efficient. Cass ([20], p.214) observed, in general, a periodic path can be efficient, or inefficient in the case where it oscillates around the Golden-Rule capital stock.

The examples of 2 period Ramsey equilibria found in Becker and Foias (1987) and Stern, as published in Becker's 2006 Survey chapter, oscillate around the Golden-Rule stock. It turns out that their 2 household examples of 2 cycle equilibrium programs are efficient. Becker and Foias assume only agent 1 has capital (the most patient individual). Stern's example has the second household holding capital infinitely often; the first household always has capital.

Becker and Foias's example has the following piecewise linear production function structure:

$$
f(k)=\left\{\begin{array}{c}
10+5 k, 0 \leq k \leq 10 \\
52+\frac{4}{5} k, k \geq 10
\end{array}\right.
$$

Note: the piecewise linear functional form can be smoothed to satisfy the conditions necessary to invoke Malinvaud's Theorem as well as apply Ramsey equilibrium theory. This example, and the ones developed by Stern ([38]) and Sorger ([36], [37]) fail the capital income monotonicity test (otherwise, the paths would be convergent). 
Let $K_{0}=12:=K_{H}$ and let $K_{L}=8$, with $f^{\prime}(8)=5$ and $f^{\prime}(12)=\frac{4}{5}$. Note that the Golden-Rule Stock occurs at $k=10$ where we note that 1 is a supergradient of $f$ at $K^{g}=10$. The path $\{12,8,12,8, \ldots\}$ can be shown to be an equilibrium 2 cycle capital sequence for appropriate choices of the discount factors and utility functions for the two households. Compute $p_{t}$ to find:

$$
p_{t}=\left\{\begin{array}{c}
1 / 4^{(t / 2)} \text { if } t \text { is even number; } \\
1.25 / 4^{(t-1) / 2} \text { if } t \text { is an odd number }
\end{array}\right.
$$

Here, $p_{0}=1$. Observe that the sequence $\left(p_{t}\right) \rightarrow 0$; this implies the equilibrium prices in this period 2 capital sequence is efficient by Malinvaud's Theorem. It turns out that two period equilibria are always efficient (see Section 5.3.2).

\subsection{The Efficiency Theorem}

The previous examples have one common feature: the definition of an appropriate system of shadow prices to check the Malinvaud Sufficiency Theorem is readily available from the detailed knowledge of the equilibrium aggregate capital sequence. It is known that other equilibrium dynamics for the aggregate capital sequence are possible than being monotonic or cycling with period 2 . The goal of this section is to offer a general sufficient condition to detect efficiency of a Ramsey equilibrium capital sequence: the first household eventually has a positive capital stock and maintains a positive stock for all subsequent times. All known examples of Ramsey equilibria satisfy this hypothesis. This condition is weaker than those implying the turnpike property.

The No Arbitrage Inequality (4) may be rewritten for each $h$ in a given equilibrium as

$$
\frac{\delta_{h} u_{h}^{\prime}\left(c_{t+1}^{h}\right)}{u_{h}^{\prime}\left(c_{t}^{h}\right)} \leq \frac{1}{f^{\prime}\left(K_{t}\right)} \text { for each } t \geq 1 .
$$

The left-hand side of (10) is $h$ 's subjective intertemporal discount factor for consumption in period $t+1$ when viewed at time $t$. The right-hand side is the corresponding market discount factor (reciprocal of the market interest factor). The inequality (10) is a necessary condition for optimality for this household. Moreover, if $x_{t}^{h}>0$, then (10) is an equality.

Define agent $h$ 's subjective present value consumption price at time $t$ by the formula:

$$
p_{t}^{h}:=\delta_{h}^{t-1} u_{h}^{\prime}\left(c_{t}^{h}\right) ; \text { with } p_{0}^{h} \equiv 1 .
$$

Using this definition, and re-writing (10) yields

$$
\frac{p_{t+1}^{h}}{p_{t}^{h}} \leq \frac{1}{f^{\prime}\left(K_{t}\right)}=\frac{p_{t+1}}{p_{t}}
$$

for each $t \geq 1$ and with equality if $x_{t}^{h}>0$. Along an equilibrium path some agent always has positive capital, so (12) holds as an equality for some agent at each time. 
Lemma 3 Make Assumptions I-III. Let $\left\{1+r_{t}, w_{t}, K_{t-1}, c_{t}^{h}, x_{t-1}^{h}\right\}$ be a Ramsey equilibrium for an economy $\mathcal{E}$. Then $\left\{p_{t}^{1}=\delta_{1}^{t-1} u_{1}^{\prime}\left(c_{t}^{1}\right)\right\}$ with $p_{0}^{1} \equiv 1$, satisfies

$$
\sum_{t=0}^{\infty} p_{t}^{1}<\infty
$$

and therefore the transversality condition holds:

$$
\lim _{t \rightarrow \infty} p_{t}^{1}=0 .
$$

Proof. The strict concavity of $u_{1}$ and $\eta^{1}=\inf _{t} c_{t}^{1}>0$ (by (P4)) imply for the given equilibrium path that

$$
0<u_{1}^{\prime}\left(c_{t}^{1}\right) \leq u_{1}^{\prime}\left(\eta^{1}\right)<\infty
$$

(13) and (14) follow.

This prepares us for the main Efficiency Theorem:

Theorem 4 Make Assumptions I-III. Let $\left\{1+r_{t}, w_{t}, K_{t-1}, c_{t}^{h}, x_{t-1}^{h}\right\}$ be a Ramsey equilibrium for an economy $\mathcal{E}$. Suppose there is some positive integer $T$, such that for each $t \geq T, x_{t}^{1}>0$. Then

$$
\sum_{t=0}^{\infty} p_{t}<\infty
$$

holds and the equilibrium program's capital stock sequence is efficient.

Proof. Using (12), we obtain for all $t \geq T$,

$$
\frac{p_{t+1}^{1}}{p_{t}^{1}}=\frac{1}{f^{\prime}\left(K_{t}\right)}=\frac{p_{t+1}}{p_{t}}
$$

This yields (by iteration on (17)) for all $t \geq T$,

$$
\frac{p_{t+1}^{1}}{p_{T}^{1}}=\frac{p_{t+1}}{p_{T}}
$$

Since (13) holds by Lemma 3, (18) implies that (16) must obtain. Thus, we have $p_{t} \rightarrow 0$ as $t \rightarrow \infty$, and $\left\{K_{t}\right\}$ is efficient by Malinvaud's Sufficiency Theorem.

\subsection{Applications of the Efficiency Theorem}

Several applications illustrate the Efficiency Theorem. 


\subsubsection{Multiple, Periodic and Chaotic Equilibria}

Sorger ([36], Theorem 1) proved it is possible for an economy $\mathcal{E}$ satisfying $(A I)$ (AIII), given the equilibrium $\left\{1+r_{t}, w_{t}, K_{t-1}, c_{t}^{h}, x_{t-1}^{h}\right\}$ with the fixed initial condition $\mathbf{k}$, to exhibit multiple equilibria from the same initial conditions. He shows there are economies for which there is a stationary equilibrium with $k^{1}=$ $K^{\delta_{1}}=\mathbf{k}, k^{h}=0$, and another equilibrium from the same initial distribution of the capital stock $\mathbf{k}$ having period $p$, where $p$ is a natural number, $p \geq 3$. That is, there are two equilibrium programs from the same initial distribution of capital. In his constructed Ramsey equilibria, the most patient household always holds the entire capital stock, and therefore the Efficiency Theorem implies that both equilibria are efficient. That is, the resulting aggregate consumption of the $p$ periodic equilibrium profile does not provide more consumption than the steady state aggregate consumption in some period without providing less than the aggregate steady state consumption in some other time period. Similarly, the chaotic equilibria found by Sorger [37] are also efficient. The latter paths cannot be computed exactly, but the Efficiency Theorem guarantees that the resulting aggregate capital sequences are efficient.

\subsubsection{Two Cycles Are Efficient}

A Ramsey Equilibrium $\left\{\left(1+r_{t}\right), w_{t}, K_{t-1}, c_{t}^{h}, x_{t-1}^{h}\right\}$ is a period two Ramsey Equilibrium cycle if there exist $\hat{x}$ and $\bar{x}$ in $\mathbb{R}_{+}^{H}$ with $\hat{x} \neq \bar{x}$, such that:

$$
x_{t} \equiv\left(x_{t}^{1}, \ldots, x_{t}^{H}\right)= \begin{cases}\hat{x} & \text { for } t=0,2,4, \ldots \\ \bar{x} & \text { for } t=1,3,5, \ldots\end{cases}
$$

Proposition 5 Let $\left\{\left(1+r_{t}\right), w_{t}, K_{t-1}, c_{t}^{h}, x_{t-1}^{h}\right\}$ be a period two Ramsey Equilibrium cycle. Then:

(a) $x_{t}^{1}>0$ for all $t \geq 0$, and

(b) the Ramsey Equilibrium is efficient.

Proof. Since $\left\{\left(1+r_{t}\right), w_{t}, K_{t-1}, c_{t}^{h}, x_{t-1}^{h}\right\}$ is a period two Ramsey Equilibrium cycle, there exist $\hat{x}$ and $\bar{x}$ in $\mathbb{R}_{+}^{H}$ with $\hat{x} \neq \bar{x}$, such that:

$$
x_{t} \equiv\left(x_{t}^{1}, \ldots, x_{t}^{H}\right)= \begin{cases}\hat{x} & \text { for } t=0,2,4, \ldots \\ \bar{x} & \text { for } t=1,3,5, \ldots\end{cases}
$$

Define $\hat{K}=\sum_{h=1}^{H} \hat{x}^{h}$ and $\bar{K}=\sum_{h=1}^{H} \bar{x}^{h}$. Then, we have:

$$
K_{t}=\left\{\begin{array}{cc}
\hat{K} & \text { for } t=0,2,4, \ldots \\
\bar{K} & \text { for } t=1,3,5, \ldots
\end{array}\right.
$$

Without loss of generality, let $\bar{K}=\max \{\hat{K}, \bar{K}\}$. [Note that $\hat{K}=\bar{K}$ is not ruled out]. Then, by (the third listed property of equilibria) we have:

$$
\bar{K}=\lim _{t \rightarrow \infty} \sup K_{t} \geq K^{\delta_{1}}
$$


and therefore:

$$
\delta_{1} f^{\prime}(\bar{K}) \leq \delta_{1} f^{\prime}\left(K^{\delta_{1}}\right)=1
$$

To establish (a), we analyze two cases separately. We have either (i) $\bar{x}^{1}=0$, or (ii) $\bar{x}^{1}>0$.

Case (i)

In this case, there is some $h \in\{2, \ldots, H\}$, such that $\bar{x}^{h}>0$. Without loss of generality, denote this $h$ by 2 . Then, $\bar{x}^{2}>0$ and by the Recurrence Theorem, $\hat{x}^{2}=0$

Pick any $T \in\{1,3,5, \ldots\}$. Then $K_{T}=\bar{K}$, and $x_{T}^{2}=\bar{x}^{2}>0$, while $x_{T+1}^{2}=$ $x_{T-1}^{2}=\hat{x}^{2}=0$. Then,

$$
c_{T}^{2}=w_{T}+\left(1+r_{T}\right) x_{T-1}^{2}-x_{T}^{2}=w_{T}-x_{T}^{2}<w_{T}
$$

and

$$
\begin{aligned}
c_{T+1}^{2} & =w_{T+1}+\left(1+r_{T+1}\right) x_{T}^{2}-x_{T+1}^{2} \\
& =w_{T+1}+\left(1+r_{T+1}\right) x_{T}^{2}>w_{T+1}
\end{aligned}
$$

Further,

$$
K_{T}=\bar{K}=\max \{\bar{K}, \hat{K}\} \geq \hat{K}=K_{T-1}
$$

so that:

$$
\begin{aligned}
w_{T+1} & =\left[f\left(K_{T}\right)-K_{T} f^{\prime}\left(K_{T}\right)\right] / H \\
& \geq\left[f\left(K_{T-1}\right)-K_{T-1} f^{\prime}\left(K_{T-1}\right)\right] / H \\
& =w_{T} .
\end{aligned}
$$

Thus, (23), (24) and (25) imply:

$$
c_{T+1}^{2}>c_{T}^{2} .
$$

Since $x_{T}^{2}>0$, we have the Ramsey-Euler equation:

$$
\frac{u_{2}^{\prime}\left(c_{T+1}^{2}\right)}{u_{2}^{\prime}\left(c_{T}^{2}\right)}=\frac{1}{\delta_{2} f^{\prime}\left(K_{T}\right)}
$$

Combining (27) and (28), we get:

$$
\delta_{2} f^{\prime}\left(K_{T}\right)>1
$$

But, by using (22), we have:

$$
\delta_{2} f^{\prime}\left(K_{T}\right)<\delta_{1} f^{\prime}\left(K_{T}\right)=\delta_{1} f^{\prime}(\bar{K}) \leq \delta_{1} f^{\prime}\left(K^{\delta_{1}}\right)=1
$$

which contradicts (29). Thus case (i) cannot arise.

Case (ii)

In this case, we have $\bar{x}^{1}>0$. We claim now that:

$$
\hat{x}^{1}>0
$$


If the claim were not true, then $\hat{x}^{1}=0$. Pick any $T \in\{1,3,5, \ldots\}$. Then, $K_{T}=\bar{K}$ and $x_{T}^{1}=\bar{x}^{1}>0$, while $x_{T-1}^{1}=x_{T+1}^{1}=\hat{x}_{1}=0$. Now, following steps (23)-(28) above, replacing household 2 by household 1 , we get:

$$
\delta_{1} f^{\prime}\left(K_{T}\right)>1
$$

But, by using (22), we have:

$$
\delta_{1} f^{\prime}\left(K_{T}\right)=\delta_{1} f^{\prime}(\bar{K}) \leq \delta_{1} f^{\prime}\left(K^{\delta_{1}}\right)=1
$$

which contradicts (31). This establishes our claim (30). Thus, $x_{t}^{1}>0$ for all $t \geq 0$, proving part (a) of the Proposition.

Part (b) follows directly from part (a) and Theorem 4.

\subsubsection{Maximum Consumption Value}

There is an interesting corollary that follows from the Efficiency Theorem. The sequence of aggregated consumption defined by the given Ramsey equilibrium path, $\left\{\left(\sum_{h=1}^{H} c_{t}^{h}\right)\right\}$, is bounded (from above, by the maximum sustainable stock, $B)$. Hence,

$$
\sum_{t=1}^{\infty} p_{t}\left(\sum_{h=1}^{H} c_{t}^{h}\right)<\infty
$$

holds as well and the conditions are met to apply a result obtained by Cass and Yaari [22] to conclude the following about the maximum value of aggregate consumption in a Ramsey equilibrium:

Corollary 6 Make Assumptions I-III. Let $\left\{1+r_{t}, w_{t}, K_{t-1}, c_{t}^{h}, x_{t-1}^{h}\right\}$ be a Ramsey equilibrium for an economy $\mathcal{E}$. Suppose, in addition, for this equilibrium, there is a time $T<\infty$ such that $t \geq T$ implies $x_{t}^{1}>0$. Then, for any feasible consumption program $\left\{c_{t}\right\}$ starting from the same initial stocks $\boldsymbol{k}$,

$$
\sum_{t=1}^{\infty} p_{t} c_{t} \leq \sum_{t=1}^{\infty} p_{t}\left(\sum_{h=1}^{H} c_{t}^{h}\right),
$$

where $\left\{p_{t}\right\}$ is defined by $(P)$. That is, the present discounted value of aggregate consumption is maximized in a Ramsey equilibrium calculated at the system of shadow prices $\left\{p_{t}\right\}$.

Proof. Cass and Yaari's [22] theorem and its corollary apply to yield the conclusion since the given Ramsey equilibrium is efficient.

This Corollary answers the basic question posed in the introduction. It gives a precise sense in which society achieves as much consumption as possible from its economic system. Here, the maximum consumption possibility is measured by the discounted value of the equilibrium aggregate consumption stream.

The Efficiency Theorem and its Corollary focuses on aggregate consumption and capital accumulation. The marginal valuations in the shadow prices 
reflect the private consumption values of agents holding capital, and who implicitly have the largest willingness to pay for a marginal unit of the composite consumption-capital good at each time. Their marginal valuations agree with the market's valuation, which reflects capital's marginal productivity at each time. The sufficiency condition insures the long-run foresight of the most patient agent is reflected in the price system. The invisible hand promotes the economy's efficient allocation of its scarce capital as the most patient agent pursues its self-interest.

\section{Malinvaud's Sufficiency Condition}

The application of Malinvaud's Sufficiency Theorem is shown to follow once (2) is verified. The assumptions needed to do so on the production function are weaker than those expressed in Assumption I.

Assume that $f: \mathbb{R}_{+} \rightarrow \mathbb{R}_{+}$satisfies the following:

(F.1) $f(0)=0, f$ is increasing, concave and continuous on $\mathbb{R}_{+}$.

Note that for all $x>0$, the left-hand derivative of $f$ at $x$, denoted by $h(x)$, is well-defined and positive.

If $\left\{K_{t}\right\}$ is a feasible capital program from $k_{0}>0$, and $K_{t}>0$ for all $t \geq 0$, then by defining:

$$
p_{0}=1, p_{t+1}=p_{t} / h\left(K_{t}\right) \text { for all } t \geq 0
$$

the sequence $\left\{K_{t}, p_{t}\right\}$ is intertemporal profit maximizing, and $p_{t}>0$ for all $t \geq 0$.

In order to show that a feasible capital program $\left\{K_{t}\right\}$ starting from $k_{0}>0$, and satisfying $K_{t}>0$ for all $t \geq 0$, is efficient, it suffices to verify that (2) is satisfied at the specific price sequence $\left\{p_{t}\right\}$, defined in (33).

Assume, in addition to (F.1), that $f$ satisfies:

(F.2) There is $0<B<\infty$, such that (i) for all $0<x<B$, we have $f(x)>x$, and (ii) for all $x>B$, we have $f(x)<x$.

Under this additional assumption, any feasible capital program $\left\{K_{t}\right\}$ starting from $k_{0} \in[0, B]$ satisfies $K_{t} \leq B$ for all $t \geq 0$. Consequently, in order to show that a feasible capital program $\left\{K_{t}\right\}$ starting from $k_{0} \in(0, B]$, and satisfying $K_{t}>0$ for all $t \geq 0$, is efficient, it suffices to verify that:

$$
\lim _{t \rightarrow \infty} p_{t}=0
$$

at the specific price sequence $\left\{p_{t}\right\}$, defined in (33).

\section{Conclusion}

The proof that Ramsey equilibria are efficient relied on an auxilliary assumption on equilirium sequences rather than conditions soley placed on the model's economic primitives governing tastes, endowments, and technology. One open 
problem is to verify that all Ramsey equilibria are efficient. The two-cycle Proposition hints that the difficulties in showing this might lie in better understanding properties of higher order periodic solutions or even chaotic ones, at least when there are two households. Indeed, any candidate for an inefficient equilibrium with two agents would necessarily require that the first household enter a zero capital state infinitely often.

Our efficiency demonstration shows the robustness of Malinvaud's criterion, which was conceived before this equilibrium model was even developed. It is perhaps a surprise that the borrowing constrained Ramsey equilibrium model still allocates society's scarce capital efficiently. But, this says nothing about how the economy's consumption is actually distributed across agents since efficiency only applies to aggregate consumption sequences. A major remaining problem is to examine the model for second best or constrained Pareto optima.

In such a study, the constraints on optimality would reflect the limitations on intertemporal exchange derived from the borrowing constraints.

\section{References}

[1] Fernando Alvarez and Urban J. Jermann, "Efficiency, Equilibrium, and Asset Pricing with Risk of Default," Econometrica, 68 (2000), 775-798.

[2] Robert A. Becker, "On the Long-Run Steady State in a Simple Dynamic Model of Equilibrium with Heterogeneous Households," Quarterly Journal of Economics, 95 (1980), 375-382.

[3] Robert A. Becker, "Equilibrium Dynamics with Many Agents," in Handbook of Optimal Growth 1 (Rose-Anne Dana, Coung Le Van, Tapan Mitra, and Kazuo Nishimura, eds.), Springer-Verlag, 2006.

[4] Robert A. Becker and John H. Boyd III, Capital Theory, Equilibrium Analysis and Recursive Utility, Basil Blackwell Publishers, Malden, MA, 1997.

[5] Robert A. Becker, John H. Boyd III, and Ciprian Foias, "The Existence of Ramsey Equilibrium," Econometrica, 59 (1991), 441-460.

[6] Robert A. Becker and Ciprian Foias, "A Characterization of Ramsey Equilibrium," Journal of Economic Theory, 41 (1987), 173-184.

[7] Robert A. Becker and Ciprian Foias, "Convergent Ramsey Equilibria," Libertas Mathematica, 10 (1990), 41-52.

[8] Robert A. Becker and Ciprian Foias, "The Local Bifurcation of Ramsey Equilibrium," Economic Theory, 4 (1994), 719-744.

[9] Robert A. Becker and Ciprian Foias, "Implicit Programming and the Invariant Manifold for Ramsey Equilibria," in Functional Analysis and Economic Theory (Yuri Abramovich, Evgenious Avgerinos, and Nicholas Yannelis, eds.), Springer-Verlag, 1998. 
[10] Robert A. Becker and Eugene N. Tsyganov, "Ramsey Equilibrium in a Two-Sector Model with Heterogeneous Households," Journal of Economic Theory, 105 (2002), 188-225.

[11] Lawrence M. Benveniste, "Two Notes on the Malinvaud Condition for Efficiency of Infinite Horizon Programs," Journal of Economic Theory, 12 (1976), 338-346.

[12] Lawrence M. Benveniste, "A Complete Characterization of Efficiency for a General Capital Accumulation Model," Journal of Economic Theory, 12 (1976), 325-327.

[13] Lawrence M. Benveniste and David Gale, "A Short Proof of Cass' Theorem on Capital Overaccumulation," Working Paper ORC 74-12, Operations Research Center, College of Engineering, University of California, Berkeley, April 1974.

[14] Lawrence M. Benveniste and David Gale, "An Extension of Cass' Characterization of Infinite Efficient Production Programs," Journal of Economic Theory, 10 (1975), 229-238.

[15] Lawrence M. Benveniste and Tapan Mitra, "Characterizing Inefficiency of Infinite-Horizon Programs in Nonsmooth Technologies," in General Equilibrium, Growth and Trade (Jerry R. Green and José A. Scheinkman, eds.), Academic Press, New York, (1979), 199-216.

[16] Truman Bewley, "An Integration of Equilibrium Theory and Turnpike Theory," Journal of Mathematical Economics, 10 (1982), 233-267.

[17] Gaetano Bloise, "Efficiency and Prices in Economies of Overlapping Generations," Journal of Economic Theory, 141 (2008), 200-224.

[18] Gaetano Bloise and Filippo L. Calciano, "A Characterization of Inefficiency in Stochastic Overlapping Generations Economies," Journal of Economic Theory, 143 (2008), 442-468.

[19] Gaetano Bloise and Pietro Reichlin, "Asset Prices, Debt Constraints and Efficiency," Working Paper, Department of Economics, Rome III, Italy, March 2009.

[20] David Cass, "On Capital Overaccumulation in the Aggregative, Neoclassical Model of Economic Growth: A Complete Characterization," Journal of Economic Theory, 4 (1972), 200-223.

[21] David Cass, "Distinguishing Inefficient Competitive Growth Paths: A Note on Capital Overaccumulation and Rapidly Diminishing Future Value of Consumption in a Fairly General Model of Capitalistic Production," Journal of Economic Theory, 4 (1972), 224-240. 
[22] David Cass and Menahem E. Yaari, "Present Values Playing the Role of Efficiency in the One-Sector Growth Model," Review of Economic Studies, 38 (1971), 331-339.

[23] Subir Chattopadhyay and Piero Gottardi, "Stochastic OLG Models, Market Structure, and Optimality," Journal of Economic Theory, 89 (1999), 21-67.

[24] Subir Chattopadhyay, "The Cass Criterion, the Net Dividend Criterion, and Optimality," Journal of Economic Theory, 139 (2008), 335-352.

[25] Jeffrey L. Coles, "Equilibrium Turnpike Theory with Constant Returns to Scale and Possibly Heterogeneous Discount Factors," International Economic Review, 26 (1985), 671-679.

[26] Jeffrey L. Coles, "Equilibrium Turnpike Theory with Time-Separable Utility," Journal of Economic Dynamics and Control, 10 (1986), 367-394.

[27] Jorge Durán and Cuong Le Van, "Simple Proof of Existence of Equilibrium in a One-Sector Growth Model with Bounded or Unbounded Returns From Below," Macroeconomic Dynamics, 7 (2003), 317-332.

[28] Cuong Le Van and Yiannis Vailakis, "Existence of a Competitive Equilibrium in a One-Sector Growth Model with Heterogeneous Agents and Irreversible Investment," Economic Theory, 22 (2003), 743-771.

[29] Edmond Malinvaud, "Capital Accumulation and Efficient Allocation of Resources," Econometrica, 21 (1953), 233-268.

[30] Tapan Mitra, "A Note on Efficient Growth with Irreversible Investment and the Phelps-Koopmans Theorem," Journal of Economic Theory, 18 (1978), 216-223.

[31] Tapan Mitra, "Identifying Inefficiency in Smooth Aggregative Models of Economic Growth: A Unifying Criterion," Journal of Mathematical Economics, 6 (1979), 85-111.

[32] Trout Rader, The Economics of Feudalism, Gordon and Breach, New York, 1971.

[33] Trout Rader, Theory of General Economic Equilibrium, Academic Press, New York, 972.

[34] Trout Rader, "Utility Over Time: The Homothetic Case," Journal of Economic Theory, 25 (1981), 219-236.

[35] Frank P. Ramsey, "A Mathematical Theory of Saving," Economic Journal, 38 (1928), 543-559.

[36] Gerhard Sorger, "On the Structure of Ramsey Equilibrium: Cycles, Indeterminacy, and Sunspots," Economic Theory, 4 (1994), 745-764. 
[37] Gerhard Sorger, "Chaotic Ramsey Equilibrium," International Journal of Bifurcation and Chaos, 5 (1995), 373-380.

[38] Michael L. Stern, personal communication, June 1, 1998. 